\title{
Los pliegos sueltos poéticos postincunables y los romances
}

\author{
Postincunable poetic chapbooks and romances
}

\author{
Giuseppe Di Stefano \\ (Università di Pisa) \\ giuseppe.distefano@unipi.it \\ ORCID: 0000-0001-5111-1606
}

\begin{abstract}
This paper addresses the origins of the printed transmission of romances, paying special attention to the postincunable poetical chapbooks we conserve, but without losing sight of testimonies known through the Colombine catalogues. The analysis conducted demonstrates the interesting interrelationships and associations between romance texts and cancioneril poetry within these chapbooks, while simultaneously delving into a global interpretation of the phenomenon to help illuminate the poetical chapbooks' process of creation as textual and editorial products, with very deliberate and clearly intentional selections of texts which comprise small literary jewels of great editorial success. The article includes, in addition, a table of romance occurrences spanning the entire $16^{\text {th }}$ century, as well as two appendices designed to reflect on the presence of chapbooks and romances in the Colombine catalogues (Appendix I) and the complex interrelationships between chapbooks and cancioneros (Appendix II).
\end{abstract}

KEYwORDS: poetic chapbooks, post-incunabula period, romancero
RESUMEN: El estudio se centra en los orígenes de la transmisión impresa de los romances, con atención particular a los pliegos poéticos postincunables conservados, pero sin perder de vista testimonios conocidos a través de los repertorios colombinos. El análisis llevado a cabo evidencia las interesantes interrelaciones y asociaciones entre textos de romances y textos de carácter lírico-cancioneril dentro de estos cuadernillos, al tiempo que se adentra en una interpretación global del fenómeno que contribuye a desentrañar el proceso de creación de los pliegos poéticos como productos textuales y editoriales conformados por selecciones muy pensadas y claramente intencionales de textos que configuran pequeñas joyas literarias de notable éxito editorial. El artículo incluye, además, una tabla de ocurrencias de romances que abarca la totalidad del siglo s. XVI, así como dos Apéndices en los que se reflexiona sobre la presencia de pliegos sueltos y romances en los registros colombinos (Apéndice I) y sobre las intrincadas interrelaciones entre pliegos sueltos y cancioneros (Apéndice II).

Palabras-clave: pliegos sueltos poéticos, periodo post-incunable, romancero

Las páginas que siguen quieren ser un homenaje y un agradecimiento a los investigadores que, en las dos décadas de abertura de este milenio, ampliando, matizando y robusteciendo líneas de indagación ya trazadas en parte por prestigiosos predecesores, han dedicado sus estudios a una actualizada reseña numérica y a una enriquecida evaluación crítica de los supérstites pliegos sueltos poéticos impresos en el siglo XVI y 
especialmente en sus primeros veinte años, o sea durante la época que los historiadores de la imprenta definen como la de los post-incunables: 1501-1520 ${ }^{1}$.

Contribuye a iluminar las nuevas rutas, entre otros, Laura Puerto, quien avisa de «lo pertinente de la lupa del estudio parcelado de un corpus solo confusamente heterogéneo desde el impresionismo de la distancia» (Puerto, 2012: 269); corpus cuya exploración impone una pizca de «osada inconsciencia» (Puerto, 2006: 561). Ahora bien, animado por una «osada inconsciencia» y con lupa en la mano - aquel tipo de lupa que ejercité sobre los romances en el Cancionero de Londres, en el General, y sobre el corpus poético de Carvajales-, emprendo aquí una vereda que flanquea la gran ruta de la exploración de los romances dentro de los pliegos sueltos post-incunables. Exploré esa vereda hace más de medio siglo, con lupa menos afinada por cierto y con inconsciencia más osada al haber alargado el paseo por todo el siglo XVI. Cómo la heterogeneidad del contenido de un pliego puede quedar anulada o muy reducida bajo la lupa del investigador lo demuestran las finas lecturas de Díaz-Mas (2013). Mi atención se dirige ahora a treinta de los cien pliegos post-incunables del Anexo de Puerto (2012), que alista solamente los cuadernillos conservados $^{2}$. Estima Puerto «que no puede ser arbitrario el que hasta un tercio del corpus considerado esté encabezado por alguna pieza romanceril, en concreto 30 unidades (más de la mitad publicadas por los Cromberger): el romancero se erige, así, y en virtud de su idiosincrática sencillez temática y formal, en punto privilegiado de la intersección entre tradición "mayor" y "menor" sobre la que parece forjarse el nuevo mercado editorial» (Puerto, 2012: 266 y también 263).

Unidas por la forma métrica y atraída la «mayor» por la llana vertiente narrativa de la «menor» sin renunciar a la dimensión lírica suya propia, ambas tradiciones colaboran en la emisión de un mensaje suprasegmental que responda a gustos estéticos y aficiones temáticas y/o culturales del destinatario; colaboración que puede - y suele - incluir textos ajenos a las formas métricas dominantes. Un aviso: en la angostura de mi vereda no caben sondeos, y menos aún conclusiones, acerca del perfil socio-cultural de ese destinatario, campo muy amplio que bien cultiva la sociología de la literatura, mirando hacia la Corte o hacia la aldea. Al evaluar el caudal de romances, su distribución, el gusto de los enlaces con los textos cancioneriles y la consiguiente densidad semántica de los conjuntos en el Cancionero de Londres, hablé de una «contextualización paradigmático-dinámica» que le caracteriza frente a la «sintagmático-estática» más típica del Cancionero General; y agregaba: «Dar cuerpo a contextos con una semántica suprasegmental es la dimensión "creativa" de la actividad del impresor o del editor, variada y móvil en los pliegos, con la frecuente recomposición de sus pocos textos, más que en los espesos y complejos volúmenes» (Di Stefano, 2006: 416 y 421)3. Hacia tal dirección parecen apuntar casi la mitad de los 30 folletos que analizaré.

\footnotetext{
${ }^{1}$ Omito casi del todo las referencias bibliográficas relativas a la labor crítica antecedente; pueden hallarse en los estudios recientes que cito.

${ }^{2}$ Beltran (2005: 107-119) había ofrecido ya un Anexo muy valioso con 113 pliegos, desde 1482 hasta 1516 (muerte de Fernando el Católico), incluyendo fichas de cuadernillos no conservados.

${ }^{3}$ De los volúmenes, y en particular del «orden editorial» en el Cancionero de romances s.a., trata Higashi (2013), a partir del «ánimo organizador» perceptible ya en los pliegos, según ejemplifica en pp. 53-56. Imprescindibles Garvin (2007) y las Introducciones a las ediciones de Romanceros en facsímil al cuidado de varios especialistas publicadas por el benemérito Frente de Afirmación Hispanista de Ciudad de México.
} 
Trataré primero, por el número y la calidad de los comentarios que ha merecido, el titulado Aquí comiençan onze maneras de romances. Con sus villancetes y aqueste primero romance fue fecho al Conde de Oliua (L 52; An. 26) ${ }^{4}$. Sus textos son variaciones sobre el amor infeliz, tema esencial de la tradición cancioneril que en la forma narrativa del romance expresa un lirismo menos enrevesado; e incluso se deleita en recuperar de la tradición genuinamente romancística exempla de problemática amorosa, con finalidades demostrativas y recreativas al mismo tiempo. Y sin duda recreación les proporcionan a los lectores los dos romances tradicionales que ocupan la cara última de este pliego repleto de angustias: «Estase la gentil dama» y «Rosa fresca, rosa fresca», con su erotismo explícito el uno y su realismo anecdótico el otro, ambos no exentos de humor. Todo lo contrario de los otros dos romances tradicionales que anteceden a estos dos finales, de ellos separados por el último de los trovadorescos. Son «Ferido está don Tristán», donde muere el mítico amador, y «En los tiempos que me vi», donde la muerte acaba de llevarse a la amada. Muertes auténticas entre tanto morir simbólico.

La muerte es uno de los varios lazos que atan entre sí a las onze maneras de romances, con el refuerzo de Villancetes, Desechas y Motes, glosas amonestadoras privativas de los romances cancioneriles. Se empieza con el primero de ellos, el dedicado al conde de Oliva, cuya conclusión profetiza «los males / que vienen de cada día / a los de amor lastimados, / qu'el morir los desafía». Se sigue con el segundo, «Estando en contemplación», que en su Desecha invoca: «Coraçon, procura vida / por penar / y no muerte y descansar». Tal inversión antinómica, peculiar del amor cortés, la aclara el tercer romance, «Alterado el Pensamiento», que se declara «aquexado de la muerte / no forçosa mas de grado, / que tal muerte vida es ella / para quien tanto ha penado: / la muerte será la vida, / la vida será el cuidado, / el cuidado de servir / donde estó más olvidado». Y la Desecha registra el grito: «Lloren mis ojos / y mi coraçón / con mucha raçón». Lo comparte el protagonista del cuarto romance, añadido por Quirós, «Triste estava el cavallero», que inicia «llorando de los sus ojos» y lamentando la ausencia de la amada: es el tema de la separación (cuyos extremos trágicos cantan los dos romances tradicionales antes citados): «iQu'es de ti, todo mi bien? / ¿Qu'es de ti, señora mía? / Mi alma te va buscando, / yo solo sin compañía, / quedo triste desseando / dos mil muertes cada día», y continúa con el típico piétiner sur place de tantos textos de Cancionero. No menos infeliz pero más activo el personaje que anima una mínima dimensión narrativa en el siguiente romance, el quinto, también añadido por Quirós, «Amara yo una señora»: su pérdida determina en el amador la huida «a las montañas» y a una vida salvaje. Quedamos dentro del patrimonio de temas y motivos del

\footnotetext{
${ }^{4}$ En este remite la letra L corresponde a Londres, que custodia el folleto en su British Library, y el número es el del pliego en su edición facsímil; An. indica el Anexo de Puerto (2012) y el número es el de la ficha del pliego en el Anexo, donde se encuentran los datos de cada folleto: impresor y probable fecha de edición, contenido, correspondencia con el número del catálogo de Rodríguez-Moñino (más sus ampliaciones), etc. Las ediciones facsimilares están reseñadas en la Bibliografía de Puerto (2012), donde fácilmente se identifican las letras que abren mis remites. Para los pliegos de París he usado fotografías, indicando el pliego con la letra F y el número que tiene en la edición facsímil en prensa (véase en Bibliografía: Fernández Valladares et alii [en prensa]). De esta edición he podido conocer la parte del vol. I debida a Fernández Valladares, gracias a la disponibilidad de la autora, a quien afectuosamente se lo agradezco; mi gratitud también a Laura Puerto, que ha colaborado en la edición facsimilar y me ha comunicado la numeración de los pliegos. El pliego L52 ha sido una de las piedras de toque para valorar, en la relación problemática entre pliegos sueltos y Cancionero General, a quién atribuir el papel de deudor: cfr. Apéndice 2.
} 
mundo poético trovadoresco, bien representado en este pliego burgalés: el infeliz amador en camino es un «romero» en el texto de abertura del folleto y es el Pensamiento que llega «a las puertas del Dolor» en el tercer romance; será - después del caballero que se refugia en el monte- el que se mete «en un desierto» en el romance sexto y, en el octavo, el que aprende su desdicha al cruzarse en el camino con un «palmero» $y$, en fin, el que ha concluido su camino de amor en una prisión, según dejan intuir el lamento del protagonista, en el romance noveno, y las palabras que le dirige el Pensamiento en respuesta a su pregunta 5 .

Desdoblado consigo mismo - es el caso de sus coloquios con el Pensamiento-o frente a otro personaje, el amador es protagonista de un encuentro y entabla un diálogo. Ambos elementos rigen la estructura típica de estas composiciones. Nuestro pliego la exhibe ya en el romance de abertura, el dedicado al conde de Oliva, que reúne en medida variable casi todos los tópicos que sustentan la invención de los demás textos del pliego. En el caudal poético cancioneril relaciones y enlaces de este tipo no sorprenden, ni menos implican la génesis de cada texto. Pero, detectados entre un número corto de composiciones reunidas en el breve espacio de un pliego, pueden prestarse a sugerir algo sobre la génesis de la iniciativa editorial y tipográfica. El protagonista del primer romance informa de que ha emprendido un viaje de Valencia a Almería «por provar si ventura, / mudando, se mudaría. / Y con este pensamiento / comencé hacer mi vía». No es el Pensamiento que entra en escena y señorea algunos de los romances sucesivos; éste indica simplemente una intención, en línea con lo concreto de un exordio entre toponomástica y etapas del recorrido. Tal modalidad cesa para volver a la intención del protagonista de «mudar ventura» cuando éste se cruza con el romero. En sus lamentos, vestiduras, mote colgado en el pecho y relato sobre su visita a «las ermitas de amor / do está la santa porfía, / do se cobra la tristeça, / do se pierde el alegría», y con la profecía conclusiva (que he transcrito arriba), el romero invita al viajero a reflexionar sobre la conveniencia de renunciar al amor respecto a la búsqueda ilusoria de una ventura amorosa más favorable. Confirman tal postura las diez restantes «maneras de romances» reunidas en el pliego, sin renunciar — desde luego - a una atormentada exaltación del amor, implícita o explícita que sea. En particular, confirma lo ilusorio de esa búsqueda el romance sexto, dedicado a las vicisitudes sentimentales de otra figura histórica de la sociedad señorial valenciana. Es el texto de Quirós al Marqués de Arzeneta por los amores de la señora Fonseca. Su exordio no se diferencia mucho del que abre el romance dedicado al conde de Oliva: «Mi desventura cansada / de los males que haría, / quísome mudar la suerte / por ver si se mudaría / la tristeza y el dolor / que jamás se me partía». Ahora el camino emprendido lleva a este amador a un desierto y después a un poblado, donde lo ilusorio de la búsqueda se materializa en la visión de una fuente seca, cuya agua «a quien más la deseava / se le desaparescía / y de sed y de desseo / el alma se me salía». Una vez dormido, parece satisfacer en sueños sus ardores por lo menos con la visión del agua «tan dulce para miralla / y amarga a quien la cogía»; pero al despertar halla la fuente «más seca que no solía» mientras su alma «allí se quedó ahogada / porque assí lo merescía: / si desdichas son amores, / júzguese en la vida mía». El binomio del penúltimo verso y la moraleja implícita son la insignia del pliego, como lo son de la tradición poética trovadoresca que el pliego entero exalta y lamenta, desde su texto de exordio y en el relato del romero interrogado por el protagonista del romance. Es el romance, a su vez, relación en primera persona cuyas señas de identidad quedan declaradas en los dos topónimos de los versos

${ }^{5}$ El breve diálogo es un remedo del romance de Guarinos «Mal ovistes los franceses». 
iniciales y cuya dolencia queda aludida únicamente con el breve remite al tópico deseo de «mudar ventura». Fecho al Conde de Oliva, según declara el título del cuadernillo, el romance desdobla al protagonista: por un lado el Conde, aparente testigo de desdichas de amor ajenas más que víctima lamentosa, y por otro lado el romero, corriente portador del dolorido caveat; dolorido y conclusivo del texto. ¿El noble valenciano resulta o no afectado por la lección? Su silencio podría indicar que sí, como parece sostener el pliego entero. Un pliego que el Conde de Oliva ha sido llamado a inaugurar y como a presidir, a él dedicado con discreción y que entre sus exempla poéticos incluye las gritadas penas de amor de aquel impetuoso marqués de Cenete, Rodrigo Díaz de Bivar y Mendoza, que realmente (y fuera del romance) vio el logro favorable de su perseguida «mudanza de ventura» a pesar de quien se obstinaba en mantener como «fonseca» a la «señora» por él suspirada y solamente en sueños gozable cual visión de fuente todo lo contrario que «fonseca». Este precioso pliego, que podemos manejar gracias a un impreso burgalés, casi se nos declara como reedición de un original seguramente valenciano, con su contenido, con su Conde dedicatario y su Marqués enamorado, ambos protagonistas del ambiente aristocrático-cultural de Valencia, donde operaban Quirós y Acuña (véase Apéndice 2). Un ambiente que sin duda supo apreciar los dos pícaros ejemplos de la pena de amor que se le brindan en la página final del cuadernillo: propiamente al Levante peninsular conduce la versión más antigua de uno de esos dos romances, «Estase la gentil dama», aunque pasada de la memoria a la escritura en Italia, casi un siglo antes.

Sorprende, por cierto, la falta del romance fecho al Conde de Oliva en el valenciano Cancionero General de 1511, al mismo Conde dedicado; pero ello podría atribuirse a la indudable «escasa importancia del hecho que relaciona, en realidad irrelevante», y al mismo tiempo puede ser indicio de una primera aparición del pliego posterior a la princeps e incluso a la segunda edición del Cancionero en 1514 (Beltran, 2005-2006: 40-41). Creo que la relevancia de este romance deriva de su vinculación con el contenido ambiental y temático del pliego entero, arriba comentado, el ser pórtico de un compacto cuadernillo que se ofrece al prócer literato como sabroso homenaje, nombrándole en el título y casi retratándole en la escena que embellece el frontispicio, ilustración cuyo uso reiterado no excluye alguna vez el acierto: seguido de su paje, un caballero se va alejando de la ciudad... ¿hacia Almería o hacia el monte o hacia el desierto? Tal relevancia anclaba el romance al pliego mientras que poco o nada contaba para los fines de Hernando del Castillo al formar su Cancionero ${ }^{6}$.

Frente a la corona de textos ejemplarmente unitaria de L 52, los que reúne otro pliego burgalés de los mismos años (F 28; An. 18) no ofrecen igual coherencia de conjunto. Abre la nocturna princesa Melisenda que impone su propio cuerpo a un sorprendido conde Ayuelos, gozoso y temeroso al mismo tiempo, en una aventura que se concluye con el perdón del Rey y padre y con boda. Siguen «Caminando por mis males» de Badajoz, impropiamente definido como «Romance» ${ }^{7}$, y la Metáfora en metros que fizo Quirós a Juan Fernández d'Eredia siendo servidor de la señora Gerónima

\footnotetext{
${ }^{6}$ Anclaje quizás responsable del haber quedado L 52 y una parcial reimpresión tardía (NDicc. 658) como sus únicos testimonios dentro del patrimonio de pliegos sueltos de Quinientos llegados o atestiguados, dato que subraya Beltran, 2005-06: 24 y 32.

${ }^{7}$ Tuvo amplia fortuna editorial. Lo contienen cuatro de los pliegos post-incunables: An. 18, con texto abreviado igual que el del Cancionero General en su edición de 1511; An. 19, con texto completo como el de la edición de 1514 del Cancionero; An. 25, con texto muy cortado dentro de una Glosa; y An. 27, con texto según el Cancionero de 1514.
} 
Beneyta: estando ella en un lugar que se llama Alcáçar, textos ambos que por cierto no cantan amores afortunados. Funciona como un diminuto entremés burlesco la Copla de maldecir de Montoro a un portugues que vido vestido de muchas colores. Su tema, blanco corriente de la comicidad cancioneril, encuentra una coincidencia con los versos finales (en este pliego y en otros) de la Metáfora, cuya continuación — aquí ausente- agrega ulteriores descripciones, serias, de vestiduras simbólicas. Tal coincidencia tiene visos de intencional, considerando además que en el Cancionero General (si en él bebió el pliego ${ }^{8}$ ) el texto de Montoro estaba a poca distancia, f. 230v, del de Quirós, f. 209v y sigs. Los dos romances finales del pliego, «Durandarte, Durandarte» y «Mudádose el pensamiento», reafirman las dolencias de amor; resultan bien conectados entre sí en tema y lenguaje, si prescindimos del «matastes a Gayferos» del primer texto en lugar del originario «amastes a Gaiferos», variante — o más bien trastrueque mecánico de letras — que ofusca el sentido del romance y acaba anulando en el pliego la relación entre ambas composiciones.

Un hermoso tríptico temáticamente unitario hallamos en el pliego crombergeriano Aquí comiençan III romances glosados [...] (M II, 53; An. 24): «Estase la gentil dama», dentro de su Glosa, enlaza con el romance «Bodas se hazen en Francia», seguido de la Glosa por Quesada, siendo tema común de las dos obras la dama que se ofrece. Entre los dos textos se coloca «Olorosa clavellina» y su Glosa, también de Quesada: no es un romance, pero su contenido es la alabanza de la vistosa hermosura de la dama; una hermosura que deja encantado al Conde durante la danza en París («miro yo vuestra lindeza / que haze penar a mí»), y es exhibida en todos sus detalles por la «gentil dama» al impasible pastorcillo.

Parecido es el perfil del pliego burgalés de c. 1520 (P II, 71; An. 28), cuyo título anuncia Romance nuevo por muy gentil estilo [...]. En sus cinco textos podemos deducir enlaces entre el primero y el quinto y entre el segundo y el cuarto. En el lugar intermedio, el tercero, el Villancico «Porque me besó Perico, / porque me besó el traidor» (texto 3) entremete su licenciosa jocosidad cual paréntesis entre una parte y otra de dos series temáticas. Es una la de las dolencias de amor que conducen al amador «Por un bosque tenebroso» aterrorizándole en sueños con una horrorosa pesadilla (texto 1), o - en lo que es un mensaje en verso «a su amiga» (texto 5, no en metro de romance) - le producen tal trastorno mental que dedica la mitad de las Coplas a una lista de todos sus males bendiciendo cada uno, ya que «Bendita mi fe que crece / cuando más males sostiene», y la otra mitad a una lista repleta de maldiciones «pues que un punto no afloxas / tu porfía». En la segunda serie temática actúan dos seductoras protagonistas. Una es la Rosaflorida, señora del castillo de Rocafrida, enamorada de Montesinos, que ella invita a un encuentro «allá a riberas de Ungría» (texto 2, Glosa), ya que «[...] el glorioso torneo / del amor jamás es feo / a quien gusta su dulzor», en palabras del glosador. Palabras que confirma el exemplum de la doncella del ya citado Villancico suyo, quien confiesa a la madre que aquel traidor de Perico la había sorprendido en la cama y «[...] como se meneava / más se mostravan sabrosos / dos mil gozos que me dava / como açúcares sabrosos». La otra seductora protagonista es la obsequiada por «Paris el enamorado», el que le declara: «Véisme aquí a vuestro mandado», con su «[...] navío muy rico / de plata y oro cargado», propio de quien se define «un terrible cossario». Estamos en el texto 4, «Reina Elena, reina Elena»: al contrario de Rosaflorida con Montesinos, es Elena quien va hacia Paris, visitando su tan atractivo barco y quedando raptada, con las trescientas doncellas de su

${ }^{8}$ Lo piensa Andreoli (2005: 54-59); duda Puerto (2020: 318n). 
corteo. Siguen guerra y destrucción de Troya. Tres retratos de mujer: una, la de los dos romances tradicionales, presente con sus deseos e iniciativas; otra, la cancioneril, ausente cual destinataria del deseo pero presente con los efectos de sus desdenes; en medio, la doncellita que se complace del hurto de su virginidad en el Villancico de la vertiente poética cómico-realista, en contraste divertido con la vertiente cortés, dominada (aunque no ajena a excepciones) por «la contención, la valoración de la abstinencia, el respeto o la descarnalización ${ }^{9} \gg$.

El asomo de la vertiente cómico-realista, una variatio con la intención de aligerar la monótona tensión dominante en pliegos no solamente amorosos cancioneriles, es frecuente, no constante. No la hallamos, por ejemplo, en el pliego que ofrece el Romance de Durandarte con la glosa de Soria, y otros diversos Romances (P I, 16; An. 19). Sus textos, equipados de glosas, villancicos y desfechas, asaltan con su carga unánime de tristuras y lamentos la emotividad del lector, sin concederle descanso.

Carga idéntica le destina al lector un pliego crombergeriano (P I, 35; An. 27) que sin embargo selecciona textos en los que predomina lo narrativo variando motivos y tonos, con piezas exquisitas como la de Badajoz y la de Juan Manuel. Modélica es ya la exhaustividad del título: Romance de la mora Moraima: glosado [por Pinar]. Otro romance que dize: Por mayo era por mayo: glosado [por Núñez]. Otro romance de Garcisanchez de Badajoz que dize: Caminando por mis males. Otro romance de don Juan Manuel que dize: Gritando va el cavallero. Otro romance del comendador Avila que dize: Descúbrase el pensamiento. La abertura con dos romances tradicionales dentro de sus glosas, unidos por la voz femenina que lamenta el engaño padecido, acentúa la fruición artístico-literaria del cuadernillo además de la temática. Gran productor de pliegos sueltos, Jacobo Cromberger descuella, sobre todo en la primera época de su actividad, por el cuidado en la ejecución material de los cuadernillos y en la composición de su contenido, y por una vinculación menos acentuada con el Cancionero General como fuente textual ${ }^{10}$. Y en el taller de Cromberger (pero utilizo un ejemplar impreso en Toledo por Villaquirán: Op. 13, y cfr. An. 82 y 83), parece haberse fraguado el pliego donde vuelve «Por el mes era de mayo» glosado por Garci Sánchez de Badajoz, así encabezado: Glosa del romance Por el mes era de mayo. Que hizo Garcisanchez de Badajoz estando preso en una torre. La qual embió a su amiga: dize el romance assi. Lo que nos dice este pliego, antes de que el género editorial llegara a ser un tesorillo en el mercado de la bibliofilia, es que bastaban dos hojas (cuantas son las suyas), la mano de un experto y el genio de un poeta auténtico para regalarle al lector una pequeña joya artística donde los topoi poéticos corrientes bien se encadenan unos con otros y se vitalizan con la acertada apariencia de un auténtico caso personal. Los tres textos que reúne, las Maldiciones, el Sueño y la Glosa son marcos y momentos de la unitaria constante lamentación, así como el buitre de las primeras, el

\footnotetext{
${ }^{9}$ Beltran (2002: 186 y passim), con la oportuna definición de la corriente realista -a la luz del tipo de transmisión que nos la documenta- como «una sub-literatura cortés más que como una sub-literatura popular» (2002: 211).

${ }^{10}$ Puerto (2006: 559); Beltrán (2005: 88-90) y, obviamente, la summa de Griffin (1991: 72). Atribuir al impresor-titular de la imprenta una responsabilidad en la selección y organización de los textos en el pliego es una cómoda simplificación, quizás incluso en el caso de Jacobo Cromberger. Remitir a asesores cultos, ocasionales, sería más verosímil, en particular frente a ciertos cuadernillos, aunque no todas las imprentas disponían de ellos. Digamos que el remite al titular de la imprenta es oportuno entenderlo como referencia al taller más que a la persona.
} 
lindo ruiseñor con las aves del segundo y la avecilla de la tercera son los testigos de una fugaz breve esperança y de la inevitable duradera mal andança.

Donde la temática no estimula operaciones exegéticas es en los pliegos con textos que podríamos definir como «noticieros» y en general celebrativos o deprecativos, los menos, de acontecimientos y personajes de la historia o de la crónica. Es el caso del pliego con título alusivo solamente a la primera de sus composiciones, sin duda la más cautivadora, también para el oído: Coplas sobre lo acaescido en la Sierra Bermeja y de los lugares perdidos. Tienen la sonada de los comendadores (Port. 5; An. 30). A esta notoria lamentación sigue la de «la triste Reina de Nápoles» sobre las muertes que la han rodeado, empezando por la del esposo hasta llegar a la amenaza francesa contra su reino, evitada gracias al socorro del Gran Capitán, enviado por los Reyes Católicos, y a la consiguiente implícita anexión de Nápoles a la Corona española. Recargan lo sombrío del pliego un par de Villancicos moralizantes para satisfacer a «quien amasse a la tristeza / y olvidasse el alegría», los oyentes convocados por la «triste Reina». Pero nuestro pliego se propone evitar a sus lectores el olvido de la alegría, reservándoles en el final tema y sones muy otros: vienen de las Coplas fechas por Rodrigo de Reynosa a unas serranas al tono del baile del villano, cultivando y alimentando la alegría entre música y danzas, amoríos y buenas raciones de comida pastoril. La faceta cómico-realista de la tradición cancioneril funciona cual despedida, o interludio a veces, según vimos antes.

A otro impreso de Cromberger (V 11; An. 23), unitario en su temática amorosa cancioneril, exaltada por textos emblemáticos como «Dezime vos, Pensamiento», o «Gritando va el cavallero», le debemos el injerto de un romance noticiero, el de Juan de Leyva a la muerte de don Jorge Manrique de Lara, no del todo impropio, por el perfil del difunto y por cómo se sitúa el texto en el cuadernillo. Muerto de una fiebre violenta en 1493 a los treinta años escasos, Manrique de Lara fue llorado y celebrado como «norte y espejo de toda gentileza», en palabras de Fernández de Oviedo, y el romance informa que «quedaron todas las damas / sin consuelo ni alegría» mientras «cada uno de los galanes / con sus lágrimas dezía: / el mejor de los mejores / oy nos dexa en este día». Aparte los tópicos, en efecto la emoción colectiva fue auténtica y sonada, tanto que el romancista concluye: «Pareciome Barcelona / a Troya cuando se ardía». Y para que el lector sepa o recuerde el porqué de tal comparación, el impresor en seguida le ofrece el romance «Triste está el rey Menalao», el lamento que es preludio al arder de Troya ${ }^{11}$. Sumando motivos de nuestro texto y de su propia Deshecha con los de la Desfecha del que precede, se extrae la moraleja del final del cuaderno: no vale oponerse a «lo que Ventura concierta». Y a designios de Ventura responden las desventuras cantadas y glosadas en «Rosa fresca, rosa fresca» y en su aparente apéndice, el «Estando desesperado» cuyo Villancico lanza un «Todos duermen coraçón, / todos duermen y vos no», que parece acogido en seguida por el «Durmiendo estava el cuidado» de Núñez ${ }^{12}$. Como víctimas de Ventura siguen «Fonte frida, fonte frida», con su Glosa cantando a la «tortolica» cuyo corazón «desventura lo partió», y «Dezime vos, Pensamiento»,

\footnotetext{
${ }^{11}$ Aunque este de Barcelona parece eco más directo de otro «arder», el de la Roma de «Mira Nero de Tarpeya», como bien anota Botta (2010: 63).

${ }^{12}$ Se oscila entre tomarla en serio o liquidarla como pura casualidad o atribuirla a un momento de humour, frente a la siguiente sucesión de textos en los fragmentos conservados del Libro de cincuenta romances: «Todas las gentes dormian», «Durmiendo estaua el cuidado» y «Yo me estaua reposando / durmiendo como solia»; entre el segundo y el tercero se infiltra «Valencia ciudad antigua», con la impertinencia ya estrenada en el Cancionero General dentro de otro contexto.
} 
donde a un «desconsolado» el «mayor dolor» que padece se le presenta cual premio, más que como condena. Premio es, en la ética trovadoresca, el dolor máximo, el «gran mal» que padece y saborea el meticuloso caballero del romance de Juan Manuel, quien «en montaña espessa [...] / hizo casa de tristura», labrada con frenético virtuosismo de símbolos y donde edifica el funéreo monumento a su amada que «murió de veinte y dos años» y «murió sin la gozar», y donde esperará que el pesar le aniquile. ¿Veríamos del todo impropia la colocación, tras este texto, del romance dedicado al caballero Manrique de Lara, «espejo de toda gentileza», muerto a sus treinta años?

Espejo de heterogeneidad tenderíamos a definir el pliego titulado Romançe de Amadís y Oriana y otro del rey Malsín: con otro del infante Gayferos: e otro que dize En Jaén está el buen Rey. Con otros dos romances (Cam; An. 21), especie de mini-antología de géneros temáticos. Es el primero el amoroso caballeresco, con Amadís y Oriana, que engancha el penúltimo de los seis textos, el amoroso cancioneril de «Por un camino muy solo» de Núñez, afín al de Amadís. Siguen: la épica pseudo-carolingia, con una variación sobre el tema de Roncesvalles, "Ya comiençan los franceses», y con «Media noche era passada» sobre el infante Gaiferos, tardío agregado a la corte del Emperante; el tema histórico del pasado, con el emplazamiento de Fernando IV en una versión de gran interés, muy contaminada en su parte final con un romance sobre Fernando I, señal de una larga vida oral antes de llegar a la imprenta, vida que debió de generar otra versión de nuestro romance, la que empieza «Válame Nuestra Señora», largo exordio contaminado con un texto sobre Fernando III el Santo. Cierra el cuadernillo el género noticiero, con la hazaña contemporánea de la Presa de Bugía en 1510, romance apologético en honor de Fernando el Católico ${ }^{13}$. Heterogeneidad indudable, pero al mismo tiempo parece evidente una organización por parejas de textos para cada especie temática, aunque vayan contiguos solamente los dos carolingios.

Queda, último de los antológicos, el pliego titulado Aquí comiençan III Romances glosados [...] (F 7; An. 25). Con un agradable equilibrio formal, ofrece «Mi padre era de Aragón» dentro de su Glosa con un Villancico, «La bella mal maridada» autónomo seguido de la Glosa de Quesada, y «Caminando por mis males» muy acortado dentro de su Glosa, y un Villancico. Una malmaridada advenediza es, respecto a la tradicional cuyo texto le sigue, la «ama buena» del primer romance, que el «Dios del cielo» quiso concederle al esclavo cristiano: lo consuela en exceso durante las ausencias del marido cazador (lo es el esposo de la malmaridada tradicional en algunas de sus versiones), quitándole la cadena, echándole en su regazo y espulgándole la cabeza y —agrega el glosador — dándole pan y vino, hasta que el cautivo «por un plazer que le hizo» recibió dinero y ayuda para la huida: «Y assí plugo a Dios del cielo / que en salvo me pusiera». No sabemos si logró conseguir igual «plazer» la malmaridada titular, que nos deja prometiendo al «cavallero gentil» lecho común, «gallinas y capones / y otras cosas más de mil». Curioso y sugestivo el enlace que parece establecerse entre el lamento de Badajoz «Caminando por mis males» y el Villancico que le sigue: el amador infeliz, huyendo del poblado, en un texto arde de «su fuego tan peligroso», mientras que en el otro pide a la zagala acogida en su cabaña ya «qu'en el monte yela, / qu'en el monte yela», refrán con que terminan la cabeza y cada una de las tres estrofas del Villancico.

${ }^{13} \mathrm{Al}$ partido fernandino atribuye Beltran (2005: 76n.) otro romance, el titulado Testamento de la reyna doña Isabel (F 24; An. 97). 
Pasemos ahora a los dieciocho pliegos con uno o dos textos amplios (y eventuales apéndices), escuetamente narrativos y de tema único ${ }^{14}$. Empezaré por los seis en que al largo texto-base le siguen algunas composiciones cortas para complementar el textobase y/o completar el cuadernillo ${ }^{15}$. Es el caso de los cuatro pliegos que presentan el Romance del conde Alarcos, uno de los best sellers de los siglos XVI y sucesivos. En un pliego le acompañan el Villancico «Pues mi triste penar» y el Villancico a Nuestra Señora «A quién devo yo llamar» [de Encina] (L 89; An. 2). La presencia de un texto de tema cancioneril al lado del Alarcos puede resultar algo anómala, un puro relleno aunque valioso. Tal presencia se repite en otro pliego (Op. 3; An. 3), donde en lugar del primer Villancico va el romance de Juan del Encina «Por unos puertos arriba», seguido del Villancico religioso. Podríamos indicar una conexión, aunque puramente exterior, entre desesperación y llantos del caminante enciniano con angustias y lágrimas del Conde cuando viaja hacia su casa para cumplir con el cruel mandado del Rey, o mejor de la Infanta. Sin embargo, una motivación más pertinente quizá pueda detectarse en una de las escenas iniciales del romance, allí donde aparece un típico tema cancioneril durante un jocoso debate entre cortesanos en una sala del Palacio Real, cuando el Conde proclama: «¿Qué aprovecha, cavalleros, / amar e servir amiga? / Que son servicios perdidos / donde firmeza no avía [...]». La «firmeza» que el Conde tópicamente exalta, contradiciendo su propia conducta sentimental efectiva, que llevará a la tragedia, es, por ejemplo, la virtud ejemplar de Amadís celebrada en el romance «Después que el esforçado» que acompaña al Alarcos en otro pliego crombergeriano en lugar del texto de Encina (F 5; An. 4). Por las mismas fechas, el impresor Coci prefiere anular tanta angustiosa armonía y al condolido lector regala el estímulo para una consoladora risotada final: el Villancico «Guárdame las vacas / Carillo y besart'é» (L 37; An. 5), más bien un relleno del pliego y no un complemento del texto-base, como pueden ser los textos amatorios e incluso los Villancicos religiosos si pensamos en el final del Alarcos.

El poemita del Conde Dirlos y de las grandes venturas que huvo ocupa tres pliegos (L 90; An. 1), dejando disponible cara y media de la hoja final, que hospeda un breve texto y su Glosa. Se trata de la composición A Nuestra Señora la Virgen María, su devoto Diego Pegera, pareja al Villancico a Nuestra Señora que acabamos de ver en el final de un par de pliegos del Alarcos. No es el mismo texto, pero curiosamente se le aproxima mucho en su construcción, iterando y glosando éste el motivo del mirar a la Virgen y aquel otro, el de Encina, el del apelarse a Ella, cual deberes y remedios salvíficos. Superfluo apuntar la falta de relación de tales textos con el Dirlos, pero no sorprende su presencia casi plegaria conclusiva que cierra una sesión de entretenimiento narrativo.

Lo mismo notamos de inmediato en el caso del brillante y rebuscado «Dos terribles pensamientos» de Encina, denominado Coplas en un pliego (L 91; An. 9) y Villancico en su reedición (F 8; An. 10), que sigue al Romance del moro Calaynos [...]. Pero cabe una reflexión. El romance cuenta del atrevido Calaínos que pierde la cabeza y la vida por mano de Roldán: acababa de llegar a Francia con la misión de cortar la cabeza de tres de los Pares y llevarlas a la infanta mora Sebilla, que se las había pedido en arras para poder concederle su amor. El texto de Juan del Encina pone en verso un dilema atormentador:

\footnotetext{
${ }^{14}$ Son pliegos definidos a veces como «monográficos», a veces como «unitarios»vs. «compuestos»: Di Stefano (1971), Di Stefano (2003: 97); Infantes (1996: 292); Puerto (2012: 268n.).

15 «Complementar»vs «completar» son términos, con la implícita diferenciación de uso del texto implicado, muy acertados que emplea Infantes (1996: 292) e Infantes (1999: 93).
} 
¿adoptar el pensamiento más «esforçado», el que «dize que muera» o el «muy temeroso», el que «dize que biva»? Y esto sabiendo que «la vida verdadera / es morir bien empleado». Y propiamente «bien empleado» ha sido el morir de Calaínos, según la ética trovadoresca y la virtud de la firmeza, a pesar de no haberse podido sustraer el moro a un retrato no tan halagador.

En sólida conexión con el poema básico, y con la obra que en él se resume, están los apéndices que completan el bellísimo pliego de gran formato y texto en cuatro columnas que propone el Romance nueuamente hecho de Calisto y Melibea [...] (San.; An. 20). Desde su cabeza, «Amor, quien de tus plazeres / y deleytes se enamora / a la fin cuytado llora», el Villancico se adhiere del todo al moralismo que inspira el romance. Compensa lo tétrico de tales tonos, en alentadora y regustada contraposición a ellos (a pesar de su incipit, que parece concordar), el romance «De la luna tengo quexa / y del sol mayor pesar»: es aquel sol que impone la separación de los amantes pero al mismo tiempo regala la visión de un cuerpo femenino «que era maravilla mirar», descrito en todos sus detalles. Innegable lo complementario, y sabrosamente complementario, con el texto-base. ¿Mueca pícara del impresor? ¿Sadismo empedernido del autor del resumen, que acababa de mostrar cuál precio pueden costar ciertos placeres?, si este autor intervino en la composición del pliego.

Inútil del todo me parece buscar nexos sobre la unión, en las dos hojas de un pliego, del Romance del conde Guarinos almirante de la mar, nuevamente trobado, como lo cativaron moros Y unas coplas de madalenica (F 27; An. 11). Basta constatar el propósito de ofrecer al lector un típico lance caballeresco y un gracioso y malicioso altercar de un galán con la sirvienta de su amada, texto de gran fortuna. Así como no permite ir más allá del admirar la elegancia del relleno, con bellos textos de Encina «Razón que fuerça no quiere» y de Santillana [i?] «Por una gentil floresta», el pliego dedicado al Romance de un desafio que se hizo en París de [...] Montesinos e Oliveros [...] por amores de [...] Aliarda, relleno que sin embargo bien prosigue y concluye el tema del poder del amor (F 29; An. 13).

Vuelve Guarinos con su hazaña en un pliego donde su texto va precedido de otro romance carolingio, «En missa está el Emperador»: Síguense dos romances por muy gentil estilo [...] (L 93; An. 12). Además del tema carolingio, los dos poemitas comparten un contenido bien surtido de invenciones extravagantes, sobre todo el primero, con el Emperador que oye misa en san Juan de Letrán, siendo Roma su residencia, y con Roldán que lamenta el poco sueldo que recibe de Carlos y el ser tratado al par de los demás Pares.

Una rápida alusión ahora a los pocos pliegos que ofrecen un solo texto cuya amplitud no deja espacio para complementos o rellenos. Es el caso de los tres post-incunables del Romance de don Gaiferos que trata de cómo sacó a su esposa que estaba en tierra de moros, otro best-seller (L 87, L 86, San.; An. 6, 7 y 8); de Otro romance del conde Claros [...] fecho por Juan de Burgos (L 7; An. 14); del Marqués de Mantua (F 3; An.16), bestseller él también; del Romance de Guiomar y del emperador Carlos [...] (P I, 25; An. 17) y del Romance nuevamente hecho por Andrés Ortiz en que se tratan los amores de Floriseo y de la reyna de Bohemia (F 6; An. 22). Es este último un resumen de la novela Floriseo [1516], dirigido a estimular la curiosidad del lector e invitarle a la compra del volumen, que casi se le visualiza al ser dotado el pliego de una verdadera portada cual un libro, caso único entre los pliegos post-incunables con romances. Lo debemos a la oficina Cromberger, la que regala a nuestra vista el gran formato del Gaiferos en tres columnas y del Calisto y Melibea en cuatro, actuales tesoros de la santanderina Biblioteca Menéndez Pelayo, todavía en espera de una reproducción facsimilar. 


\section{II}

En las páginas que anteceden he atribuido la calificación de best seller a tres romances, el Conde Alarcos, el Gaiferos libertador de su esposa y el Marqués de Mantua, sobre la base obvia del número de sus pliegos conservados. Prudencia, por lo tanto, en este caso como en toda generalización que se fragüe y exprese sobre estos cuadernillos, cuya conservación debemos a pura casualidad. Sin embargo, alguna cauta generalización podemos concedérnosla al entrever convergencias de datos, de varias fuentes y naturaleza, hacia una misma dirección. Suele ocurrir con la llamada «fortuna» de un texto, en nuestro caso circunscrita a la fortuna editorial, la documentada en sus medios canónicos de difusión, los pliegos sueltos y los romanceros, sea cual sea el título de estos últimos. Ahora bien, en todo el siglo XVI el Gaiferos alcanza 18 presencias, número máximo que comparte solamente con «Rosa fresca, rosa fresca»; el Alarcos y el Marqués de Mantua llegan a 12. Los pliegos sueltos contribuyen a estos números totales con 11 para el Gaiferos y «Rosa fresca, rosa fresca», 6 para el Alarcos y 9 para Mantua. Entre folletos y libros queda confirmada cierta diferenciación en sus selecciones. Y a este propósito merece subrayarse el caso extremo de «Triste está el rey Menalao», que llega a un total de 17 presencias gracias a la 15 que le dedican los volúmenes.

Extraigo estos datos de una encuesta que publiqué hace varios decenios y que tuve ocasión, en años recientes, de volver a publicar en parte, poniendo al día lo relativo a los solos pliegos sueltos según los nuevos hallazgos y rectificaciones ${ }^{16}$. Amplío la pequeña muestra de arriba con algún ejemplo más de entre los romances contenidos en los pliegos post-incunables. Best sellers pueden considerarse sin duda «Fonte frida, fonte frida» con 16 presencias (11 en volúmenes); tocan las 15 «Emperatrizes y reinas» y «La bella malmaridada» (4 en vols. el uno y 5 el otro); hasta las 13 llegan "Ya comiençan los franceses» (3 en vols.) y «Yo m'era mora Moraima» (8 en vols.); son 10 las de «Ferido está don Tristán» ( 2 en vols.). Entre los trovadorescos (ausentes en mi encuesta, utilizo Rodríguez-Moñino, 1997 y Askins-Infantes, 2014) se registran, solamente en los pliegos, 10 presencias para el que no es propiamente un romance, «Caminando por mis males»; quedan a alguna distancia, con 7 apariciones, «Gritando va el cavallero» y con 6 «Alterado el pensamiento», «Dezime vos, pensamiento», «Mi libertad en sossiego»y «Triste está el cavallero».

Salta a la vista lo duradero de una parte significativa de la oferta romanceril de los pliegos sueltos en sus dos decenios aurorales, destinada a una relevante presencia editorial a lo largo del siglo. De sus 59 textos en total, son 12 los que aparecen en más de un folleto post-incunable. De ellos, la mayoría (9) no supera las dos presencias, solamente 1 llega a tres y 2 alcanzan las cuatro. El de tres es el Gaiferos y los de cuatro son «Caminando por mis males» y el Alarcos, o sea un par de textos eminentemente narrativos y uno donde lo narrativo peculiar de la forma romance está al servicio de una temática y de una problemática lírico-trovadorescas. La misma proporción entre las dos vertientes temático-expresivas ofrecen los 9 romances con dos presencias: cinco narrativos, cuatro trovadorescos. Es la proporción que se observa en los pliegos romanceriles de los decenios sucesivos del siglo, con oscilaciones y variaciones obvias en número y poéticas. Dejo al lector informaciones y controles ulteriores, si curiosea en la Tabla que sigue pero teniendo siempre en cuenta el valor muy relativo de los datos numéricos y de los

${ }^{16}$ Di Stefano (1977) y Di Stefano (2019), donde el lector encontrará los criterios que presidieron a la formación del corpus y a la encuesta. 
comentarios consiguientes: la documentación disponible es una parte extremadamente mínima de lo que se produjo y circuló en el siglo XVI, en ámbito de pliegos sueltos sobre todo. Digamos que este tipo de Tablas registra apariencias, que pueden adquirir sustancia cuando se comparan de manera pertinente unas con otras.

TABLA

Van en letra cursiva los primeros versos de los romances contenidos en los pliegos del Anexo de Puerto (2012) y ausentes en HGD y HGD.N.

An. $\quad$ Anexo, seguido de su número de orden: Puerto (2012: 286-299).

HGD Homenaje a García de Diego: Di Stefano (1977: 406-410). Le siguen dos números: el primero indica las presencias del romance en pliegos y Romanceros de todo el siglo XVI, extractadas del Cuadro IX de HGD; el segundo, entre paréntesis, indica las presencias en los solos Romanceros.

HGD.N Remite al Cuadro IX de HGD puesto al día, publicado en la revista Norte (Di Stefano, 2019: 13-18). Señala los romances que en la puesta al día han aumentado sus presencias en pliegos.

Rom. I Romancero I (Di Stefano, 2017). Sigue el número de orden del texto del romance en esta recopilación, donde el lector encontrará también variantes de los testimonios de cada romance anteriores a 1520 y notas de comentario.

Alterado el pensamiento * Amadís el muy famoso

Amara yo una señora

Assentado está Gaiferos

A veinte y siete de março

Bodas se hazen en Francia

Caminando por mis males

Caminando sin plazer

De Mantua salen apriessa

De Mantua salió el marqués

Descúbrase el pensamiento

Después que el rey don Rodrigo / perdió

Dezime vos, Pensamiento,

Dígasme tú, el Pensamiento,

Durandarte, Durandarte

Durmiendo está el conde Claros

Durmiendo estava el Cuidado

Emperatrizes y Reinas

En Castilla está un castillo

En el nombre de Jesús

En el tiempo en que me vi **

En Jaén está el buen Rey

En las salas de París

En missa está el Emperador

En una parte del mundo

Estando desesperado

Estando en contemplación

Estase la gentil dama

Estávase el conde Dirlos

Ferido está don Tristán

Fonte frida, fonte frida

Gritando va el cavallero
An. 26

An. 21

An. 26

An. 6, 7, 8

An. 23

An. 24

An. 18, 19, 25, 27

An. 15

An. 16

An. 16

An. 27

An. 97

An. 23,26

An. 15

An. 19

An. 14

An. 23

An. 29,30

An. 28

An. 16

An. 15, 26

An. 21

An. 13

An. 12,15

An. 21

An. 23

An. 26

An. 24, 26

An. 1

An. 26

An. 23

An. 23, 27
Rom. I, 58.

Rom. I, 78

Rom. I, 70

Rom. I, 100

Rom. I, 140

Rom. I, 92

HGD 13 (11)

HGD 7 (4)

Rom. I, 28

HGD.N 15 (6)

HGD.N 15 (6)

Rom. I, 104

Rom. I, 103

Rom. I, 52

Rom. I, 51

HGD 15 (13)

HGD 2 (0)

HGD.N 15 (4)

HGD.N 8 (3)

HGD.N 15 (6)

HGD 7 (2)

HGD 7 (4) ***

HGD 12 (7)

HGD 4 (0)

Rom. I, 145

Rom. I, 44

Rom. I, 86

Rom. I, 6

Rom. I, 53

Rom. I, 143

Rom. I, 90

Rom. I, 105

Rom. I, 69

Rom. I, 116

Rom. I, 98

Rom. I, 108

Rom. I, 148

Rom. I, 15

Rom. I, 31

Rom. I, 88

Rom. I, 102

Rom. I, 64

Rom. I, 72

Rom. I, 67 
La bella malmaridada

Ledesma casa de Infantes $* * * *$

Mal ovistes, los franceses,

Media noche era passada

Mi Desventura cansada

Mi Libertad en sossiego

Mi padre era de Aragón

Mudado s'ha el pensamiento

Por mayo era por mayo

Por un bosque tenebroso

Por un camino muy solo

Por unos puertos arriba

...que tanto mal ha causado *****

Quien uviesse tal ventura, en averse [...]

Reina Elena, reina Elena,

Retraída está la Infanta

Rosa fresca, rosa fresca, / tan garrida [...]

Todas las gentes dormían

Triste está el rey Menalao

Triste estava el cavallero [...] pensando en su coraçón

Un caso muy señalado

Ya cavalga Calaínos

Ya comiençan los franceses

Ya desmayan mis servicios

Ya se sale Guiomar

Yo me partí de Valencia

Yo m'era mora Moraima
An. 25

HGD.N 15 (5)

An. 11, 12

An. 21

An. 19, 26

An. 19

An. 25

An. 18

An. $27,82,83$

An. 28

An. 19, 21

An. 15

An. 15

An. 22

An. 28

An. 2, 3, 4, 5

An. 23,

An. 18

An. 23

An. 20

An. 9, 10

An. 21

An. 19

An. 17

An. 26

An. 27
HGD 9 (3)

HGD 3 (1)

HGD 8 (4)

HGD 15 (10)

HGD.N 8 (1)

HGD 12 (6)

HGD.N 18 (7)

HGD.N 8 (2)

HGD 17 (15)

An. 26

HGD 7 (3)

HGD.N 13 (3)

HGD.N 3 (0)

HGD.N 13 (8)
Rom. I, 94

Rom. I, 150

Rom. I, 97

Rom. I, 99

Rom. I, 8

Rom. I, 7

Rom. I, 81

Rom. I, 47

Rom. I, 25

Rom. I, 30

Rom. I, 2

Rom. I, 69

Rom. I, 77

Rom. I, 73

Rom. I, 66

Rom. I, 84

Rom. I, 76

Rom. I, 74

Rom. I, 21

Rom. I, 65

Rom. I, 107

Rom. I, 95

Rom. I, 59

Rom. I, 106

Rom. I, 43

Rom. I, 91

*Variante: sentimiento. ** Variante: «En los tiempos». *** Junto con la versión que empieza «Válasme Nuestra Señora».**** París, Y2. 858: ¿1512?***** Es parte de un romance sobre la muerte de Felipe I en un pliego fragmentario.

\section{ApÉNDICE I}

Sabemos que las fichas de los Catálogos de la Biblioteca de Fernando Colón que no registran ninguna fecha valen, a efectos de asignar a una obra la época de su impresión, solamente como indicación ante quem, o sea ante 1539, año de la muerte de don Fernando. Las fichas que llevan la fecha de adquisición de la obra nos informan que esa obra circulaba impresa ante esa fecha. La consulta de los Catálogos colombinos llevada a cabo por Rodríguez-Moñino (1976, con una hoja de errata-corrige de Askins) da un total de 355 indicaciones; las relativas a pliegos post-incunables son, obviamente, las fichas que contienen la fecha de impresión, y son diez: las número 156 (año 1502), 258 (1506), 136 (1509), 265 (1513), 205 (1515), 315 (1515), 191 (1516), 277 (1519), 248 (1520) y 62 (1520) (Rodríguez-Moñino, 1976, passim y p. 178). En ninguno de estos pliegos hallamos textos en verso de romance y/o sobre temas trovadoresco-cancioneriles. ¿Es tan sólo una casualidad? Predominan los contenidos religiosos y moralístico-didascálicos. Solas excepciones el n. ${ }^{\circ}$ 205 (impreso en Toledo), que al Salterio agrega un texto sobre la toma de Orán y otro sobre guerras de Italia y Navarra; el n. 315 (uno de los dos pliegos impresos en Barcelona) donde al Testament de Serradell le siguen dos textos de Encina; y el n. 277 (uno de los dos pliegos impresos en Valencia) que de Ovidio saca la materia para la Contienda entre Ayax y Ulises. Los demás lugares de imprenta son Sevilla (dos pliegos) y Burgos (3 pliegos). 
A estos pliegos se pueden agregar aquellos cuyas fichas ofrecen solamente fechas de adquisición entre 1501 y 1520 y que por lo tanto es posible incluir por vía deductiva entre los impresos en los dos decenios primeros del siglo XVI. Es vía no enteramente segura, desde luego: el pliego n. ${ }^{\circ} 226$, que descartamos, en una nota resulta adquirido en 1511 y de otra aprendemos tratarse de un impreso sevillano de 1493. A los pliegos postincunables seguros agregaríamos, por lo tanto, los posibles 9 siguientes: $n{ }^{\text {os }} 253$ y 255 (adquiridos en Toledo en 1511), los n. ${ }^{\text {os }} 32,40,104$ y 246 (en Tarragona, 1513), los n. ${ }^{\text {ss }}$ 2 y 190 (en Medina del Campo, 1514) y el n. 149 (en Roma, 1515). En ellos la temática es más variada y vivaz: lo religioso está casi ausente, muy presente lo oficial e histórico, asoman un Perqué de amores y una Liga de las buenas mujeres contra los Cortesanos (pliego comprado no casualmente en la Roma teatro del Concilio de los galanes y cortesanas de Roma de Torres Naharro y de las empresas de la Lozana de Delicado, y donde Colón adquiere también una Historia de fugir le puttane, el Lamento d'una cortigiana ferrarese, un par de textos sobre el mal francés, además de un relevante número de obras de muy distintos saberes, relacionadas algunas con los cursos universitario que allí siguió). Asoman también el perdido Arte de la poesía de Juan de Mena y sobre todo - para nuestros intereses del momento - dos romances en significativa oposición entre sí en tema, estilo y fortuna: por un lado, entre los pliegos comprados en Tarragona, La bella malmaridada, duradera estrella de la tradición romancística, y por otro el solemne y celebrativo Romance de Ledesma de Juan Augur de Trasmiera, adquirido en Medina, ejemplo de prototipo de una tipología romanceril ostentosamente culta que verá proliferar sus composiciones bien entrado el siglo XVI, textos cuya aurora suele coincidir con un ocaso definitivo.

Parece que el texto de La bella malmaridada comprado en Tarragona en agosto de 1513 haya ocupado, según la ficha de Colón, él solo un pliego «en $4^{\circ} .2$ col.». Al resultar tal pliego perdido, no es posible un control de la exactitud de la ficha que documentaría un folleto con ese único texto, anomalía ya notada por Rodríguez-Moñino (1976: n. $\left.{ }^{\circ} 32\right)$. En efecto, en la ficha n. ${ }^{\circ} 25$ del Anexo de Puerto (2012), hallamos un pliego en $4^{\circ}, 2$ col., 4 hojas, impreso hacia 1520 en Sevilla por Cromberger, pero que reúne con La bella otros dos romances, los tres con sus glosas, dos de ellas seguidas de Villancicos; y en la casi decena de pliegos del XVI que conocemos, nunca La bella resulta sin compañía. Este romance se mereció un puesto en el Libro de los Epítomes, uno de los múltiples catálogos creados y en parte redactados por Hernando Colón; considerado desaparecido, recientemente ha sido descubierto, falto de varias de sus hojas, en la Biblioteca «Arnamagnaean Collection» de Copenhagen. En una de esas hojas perdidas, bajo el n. ${ }^{\circ}$ 3543, se podía leer un resumen de $L a$ bella malmaridada, según referencia en otro catálogo colombino, el Abecedarium $B$ (véase Pérez Fernández y Wilson-Lee, 2021: 149 y 279, n. 41).

A la luz de lo publicado hasta hoy a partir de los estudios de Rodríguez-Moñino, sería oportuna una catalogación definitiva de los pliegos fichados en los Registros de Colón distinguiendo, cuando posible y seguro, entre la referencia a un pliego superviviente y la referencia a un pliego no conservado o a otro ejemplar del conservado; y distinguir claramente también entre fecha de publicación del folleto apuntada en los Registros y la deducida de los mismos Registros cuando señalan solo el año de adquisición del pliego. Esto evitaría a los usuarios de los datos colombinos malas interpretaciones y confusiones. Y no solamente de los datos colombinos. Doy un ejemplo. Infantes (1981: 12n) informa que la llamada «colección De Bure» constaba de «tres volúmenes de pliegos» con los números 698, 700 y 701 en el Catalogue de su venta en 1853; y que los volúmenes 698 y 701 se custodian en la Bibliothèque Nationale de París, mientras el volumen 700, cuyo 
paradero en una Universidad norteamericana descubrió Infantes, es el que describe en el artículo que acabo de citar. Ahora bien, con frecuencia se suele aludir, sin precisiones ulteriores, a la «colección de Bure», dándola algunos como relativa a pliegos tardíos, otros como relativa a pliegos tempranos, una contradicción que tal no sería si se especificara que los tardíos son los de los volúmenes 700 y 701 y los tempranos caracterizan el volumen 698; y cuando alguna vez, aludiendo a un genérico volumen de Bure de pliegos tempranos se le atribuye un muy probable y sugestivo origen colombino, no estaría mal avisar que de los Registros de don Fernando se han deducido por lo menos diez tomos facticios con dentro pliegos sueltos, tomos cuya antigua numeración puede encontrarse esparcida en las anotaciones de Askins (1986). Precisemos que el De Bure 698 contiene 28 pliegos, fechables todos entre 1505 y 1520, cuya signatura actual va de Rés. Yg. 87 a Rés. Yg. 112; el De Bure 701 reúne 6 pliegos, fechados entre 1597 y 1598, con signatura que corre de Rés. Yg. 114 a Rés. Yg. 119; y el De Bure 700 encierra 8 pliegos, uno fechado en 1596 y los demás probablemente no mucho menos tardíos. Debo tales datos, además de a Infantes (1981), a los Índices impecables de Fernández Valladares et alii (en prensa), obra donde lo antes apuntado a propósito del estudio de los fondos de Colón encuentra un modelo magistral de método y de proceder científicos.

\section{ApÉNDICE II}

Ahondando en el muy probable origen valenciano del pliego L 52, «un arquetipo gestado en Valencia», e investigando fortuna y variantes de sus textos en páginas fundamentales (Beltran, 2005-2006: 34 y sigs., con amplia bibliografía, y Beltran, 2012: 29-30), Beltran (2016: 131) puede escribir: «Gestado en Valencia (si no ando equivocado) y luego integrado en el Cancionero General». Inversa la opinión de Garvin (2007: 55-56), que alista L 52 entre los «pliegos en los que los romances sacados de la obra de Castillo se combinaban con otras composiciones, formando productos híbridos»; y remite a los folios del Cancionero de donde provendrían trece textos de los dieciocho contenidos en el pliego (incluyendo Villancicos y Desfechas): el n. ${ }^{\text {s }} 2$ en $\mathrm{f} .138 \mathrm{r}$ del Cancionero, $\operatorname{los} \mathrm{n} .{ }^{\text {s }} 3$, 4, 6, 7, 8 y 9 en f. $138 \mathrm{v}$, el 10 en f. 139r, el n. ${ }^{\circ} 11$ en f. 129 r, los n. ${ }^{\text {os }} 14$ y 15 en f. $134 \mathrm{r}$, el n. ${ }^{\circ} 16$ en $\mathrm{f} .9 \mathrm{v}$ y el n. ${ }^{\circ} 18$, último, en f. 132; ausentes en el Cancionero son los $\mathrm{n} .^{\circ \mathrm{os}} 1,5,12$, 13 y 17, o sea cuatro romances y una Desfecha. Estos números expresan una continuidad en el «préstamo» entre los ff. 138r, donde empieza «Estando en contemplación», 138v y 139r: son ocho textos, pero las obras son cinco, considerando obra un texto base con su Villancico o Desfecha. Corresponden en el pliego a las obras n. ${ }^{\text {os }}$ 2-3, 4 (falta la Desfecha, texto n. $^{\circ} 5$ en el pliego), 6-7, 8-9 y 10-11(Desfecha, en f. 129r del Cancionero). Lo mismo ocurre con los n.$^{o s}$ del pliego 14-15-16 (Mote, en f. 9v del Cancionero), tres textos que forman una obra: texto base, su Desfecha y su Mote. Resumiendo, son siete las obras que unen L 52 y el Cancionero; son cuatro las que los separan más la ausencia de una Desfecha. Estas cuatro obras son romances tradicionales de mucha solera que bien encajan en el pliego, con sus textos desnudos de todo enriquecimiento como no los admite Hernando del Castillo, género que no desdeña si cultamente arropado. Ahora bien, en vista de lo antedicho y de los remites a los folios del magno Cancionero, como oportunamente hacen los que atribuyen a este la primacía, tendríamos que imaginarnos a un impresor de Burgos o de Sevilla o de Valencia que, después de haber «saqueado» tres folios seguidos del General, para completar el pliego fuera «hurtando» en el f. 129, «pillando» en el f. 134, «plagiando» en el f. 132 y hasta en el f. 9 dentro de la sección dedicada a las «Obras de 
devoción», de donde saca como texto del Mote el comienzo de un Villancico que cierra las «Coplas a la quinta angustia de Nuestra Señora», comienzo de las Obras de Sazedo. No es un imposible, pero...

Imposible, casi, resulta establecer quién debe a quién, incluso acudiendo a cotejos textuales entre las dos fuentes, cotejos que no dejen espacio a conjeturar una inversión del vínculo (véase arriba la nota 8). Pesa la ausencia - hasta el momento- de pliegos sueltos romanceriles fechados, o fechables de manera incontrovertible, con anterioridad al Cancionero General. Inevitable compartir la conclusión de Beltran (2018: 74): la idea de los pliegos de los primeros decenios del siglo XVI como fuertes deudores del Cancionero General, «generalmente aceptada, está falta de una verificación empírica suficiente». Pero, al mismo tiempo, debemos reconocer que interesantes aproximaciones y estímulos a esa «verificación empírica» se van realizando: remito a Garvin (2007: 55-56), citado antes, y a Garvin (2015: 9-12), donde, una vez examinado el contenido supérstite, y el referido en el título, del fragmento del Libro de cincuenta romances, se afirma la robusta deuda del Libro más para con los pliegos que con el Cancionero General, prevaleciendo los folletos impresos por Cromberger y por Basilea-Melgar. Y a Garvin (2006) debemos también un veloz pero sustancioso examen de la problemática de tal ambivalencia.

Cierro anotando un vaivén, entre los folios del Cancionero, muy distinto respecto al captado en L 52. Lo observamos en el pliego V 11 (An. 23) a la luz de la coherente organización que parece percibirse en el cuadernillo, descrita en páginas anteriores. Empezando con sus textos $\mathrm{n} .^{\text {os }} 1$ y 2 , extraídos de los ff. 132rv del Cancionero, se sigue con los que van del texto $n .^{\circ} 3$ hasta el n. ${ }^{\circ} 6$, sacados del f. $134 \mathrm{r}$, con los n. ${ }^{\text {os }} 7-8$ en el f. $133 \mathrm{r}$, con los n. ${ }^{\text {os }} 9-10$ en el f. $134 \mathrm{r}$, con los n. ${ }^{\text {os }} 11,12$ y 13 en el f. $135 \mathrm{rv}$ y con los n. ${ }^{\text {os }} 14-15$ en el f. 134v; o sea, se opera - si deuda hubo- entre los ff. del 132r al 135v del Cancionero.

Seleccionando sin saltos atrás, pero sí hacia delante, parece haber procedido la inspección del Cancionero de parte de quien preparaba el contenido del pliego P I, 16 (An. 19): desde el f. 137r con el «Durandarte, Durandarte» hasta el f. 140r con la Desfecha de «Dígasme tú, el pensamiento».

Son dos ejemplos de selecciones que debemos en primer lugar a la suerte que nos los ha conservado y después a los que les dieron vida con sus «hurtos» y demás sinónimos antes alistados; se los debemos también a los compañeros que han revitalizado una materia de estudio en la que es tan corriente el sorprender con le mani nel sacco como es inevitable la sensación de poder invertir dueño de las manos y del saco.

\section{OBRAS CITADAS}

Askins, Arthur Lee-Francis (1986): «The pliegos sueltos of the Biblioteca Colombina in the Sixteenth Century: Notes to an Inventory», Romance Philology, 39, pp. 305322.

Askins, Arthur Lee-Francis e Infantes, Víctor (2014): Suplemento al Nuevo Diccionario bibliográfico de pliegos sueltos poéticos (siglo XVI) de Antonio RodríguezMoñino, Edición de Laura Puerto Moro, Vigo, Academia del Hispanismo.

Andreoli, Massimiliano (ed.) (2005): Quirós, Poesie, Napoli, Liguori Editore.

Beltran, Vicenç (2002): «Poesía popular antigua, ¿cultura cortés?», Romance Philology, 55, pp. 183-230. DOI: https://doi.org/10.1484/J.RPH.2.304475

Beltran, Vicenç (2005): «Los primeros pliegos poéticos: alta cultura / cultura popular», Revista de Literatura Medieval, 17, pp. 71-120. 
Beltran, Vicenç (2005-2006): «Del pliego de poesía (manuscrito) al pliego poético (impreso)», Incipit, 25-26, pp. 21-56.

Beltran, Vicenç (2012): «Quinientos años de Cancionero General», en Estudios sobre el Cancionero General (Valencia, 1511): Poesía, Manuscrito e Imprenta, Marta Haro Cortés, Rafael Beltrán, José Luis Canet, Héctor H. Gassó (eds.), València, Universitat, pp. 15-35.

Beltran, Vicenç (2016), El romancero: de la oralidad al canon, Kassel, Edition Reichenberger.

Beltran, Vicenç (2018): «El romancero en la encrucijada: "Media noche era por filo" y el conde Claros de Montalbán», en Literatura Medieval (Hispánica). Nuevos enfoques metodológicos y críticos, San Millán de la Cogolla, Cilengua, pp. 59-86.

BotTA, Patrizia (2010): «Los Romances trovadorescos del Cancionero General. Un crisol de Cancionero y Romancero», en Actas del XIII Congreso Internacional de la Asociación Hispánica de Literatura Medieval. In memoriam Alan Deyermond, José Manuel Fradejas Rueda, D. Dietrick Smithbauer, D. Martin Sanz y María Jesús Díez Garretas (eds.), Valladolid, Ayuntamiento / Universidad de Valladolid, vol. I, pp. 41-66.

Díaz Mas, Paloma (2013): «Lecturas y reescrituras de romances en los Siglos de Oro: Glosas, Deshechas y otros paratextos», Edad de Oro, 32, pp.155-175.

Di Stefano, Giuseppe (1971): «Il pliego suelto cinquecentesco e il romancero», en Studi di Filologia Romanza. Offerti a Silvio Pellegrini, Padova, Liviana Editrice, pp. 111-143.

Di Stefano, Giuseppe (1977): «La difusión impresa del romancero antiguo en el siglo XVI», en Homenaje a Vicente García de Diego, publicado en Revista de Dialectología y Tradiciones Populares, 33, pp. 373-411.

Di Stefano, Giuseppe (2003): «Transcribir-transcodificar: el ejemplo del romancero», en Textualización y oralidad, José Jesús de Bustos (coord.), Madrid, Instituto Universitario Menéndez Pidal / Visor Libros, pp. 87-101.

Di Stefano, Giuseppe (2006): «El impresor-editor y los romances», en La literatura popular impresa en España y en la América colonial. Formas y temas, géneros, funciones, difusión, historia y teoría, Pedro M. Cátedra (dir.), Eva Belén Carro Carvajal, Laura Mier, Laura Puerto Moro y María Sánchez Pérez (eds.), Salamanca, Seminario de Estudios Medievales y Renacentistas / Instituto de Historia del Libro y de la Lectura, pp. 415-424.

Di Stefano, Giuseppe (ed.) (2017): Romancero I (c. 1421-1520). El primer siglo del romancero en el papel, Würzburg / Madrid, e-book, URL: <www.clasicoshispanicos.com>.

Di Stefano, Giuseppe (2019): «La difusión impresa del romancero en el siglo XVI. (Fragmentos)», en Norte. Revista Hispano-Americana, 529-530, pp. 7-21.

Fernández Valladares, Mercedes, Puerto Moro, Laura y Mahiques Climent, Joan (en prensa): Pliegos sueltos poéticos del siglo XVI en Bibliotecas de Francia. Estudio bibliográfico y literario y edición facsímil, México / Madrid, Frente de Afirmación Hispanista / Fundación Menéndez Pidal. 2 vols.

Garvin, Mario (2006): «Recontextualización de materiales cancioneriles en pliegos sueltos quinientistas», en Convivio. Estudios sobre la poesía de Cancioneros, Vicenç Beltrán y Juan Paredes (eds.), Granada, Universidad, pp. 363-373.

Garvin, Mario (2007): Scripta manent. Hacia una edición crítica del romancero impreso (siglo XVI), Madrid / Frankfurt am Main, Iberoamericana / Vervuert. DOI: https:// doi.org/10.31819/9783964562777 
GARVIN, Mario (2015): «El Libro de cincuenta romances. Historia editorial de un impreso perdido», Zeitschrift für Romanische Philologie, 131, pp. 1-21. DOI: https://doi .org/10.1515/zrp-2015-0003

GRIFFIn, Clive (1991): Los Cromberger. La historia de una imprenta del siglo XVI en Sevilla y México, Madrid, Ediciones de Cultura Hispánica.

Higashi, Alejandro (2013): «El género editorial y el Romancero», Lemir, 17, pp. 37-64.

INFANTES, Víctor (1981): «Un volumen viajero de impresos españoles del siglo XVI: los pliegos góticos de J. J. de Bure», Studi Ispanici, 6, pp. 9-21.

InFANTES, Víctor (1996):«Los pliegos sueltos del Siglo de Oro: hacia la historia de una poética editorial», en Colportage et lecture populaire. Imprimés de large circulation en Europe, XVIe-XIXe siêcles, Actes du Colloque des 21-24 avril 1991 Wolfebüttel, Roger Chartier et Hans-Jürgen Lüsebrink (eds.), Paris, IMEC Éditions / Éditions de la Maison des Sciences de l'Homme, pp. 283-298.

INFANTES, Víctor (1999): «Hacia la poesía impresa. Los pliegos sueltos de Juan del Encina: entre el Cancionero manuscrito y el libro poético», en Humanismo y Literatura en tiempos de Juan del Encina, Javier Guijarro Ceballos (ed.), Salamanca, Ediciones Universidad, pp. 83-99. Reimpreso en Conde, Juan Carlos e Infantes, Víctor: De Cancioneros manuscritos y poesía impresa. Estudios bibliográficos y literarios sobre lírica castellana del siglo XV, Madrid, Editorial ARCO/LIBROS, 2007, pp. 191-212.

Pérez Fernández, José María, y Wilson-Lee, Edward (2021): Hernando Colon's New World of Books: Toward a Cartography of Knowledge, New Haven, Yale University Press. DOI: https://doi.org/10.2307/j.ctv1b0fw2s

Puerto Moro, Laura (2006): «Hacia la definición de una retórica formal para el pliego suelto poético (1500-1520)», en La literatura popular impresa, cit. arriba sub DI SteFAno (2006), pp. 543-561.

Puerto Moro, Laura (2012): «El universo del pliego poético postincunable (del despegue de la literatura popular impresa en castellano)», eHumanista, 21, pp. 257-304.

Puerto Moro, Laura (2020): «La popularización del Cancionero: de los grandes poetas cancioneriles a los autores galantes intermedios (con un estudio de caso: Alonso de Salaya)», Revista de poética medieval, 34, pp. 315-340. DOI: https://doi.org /10.37536/RPM.2020.34.0.78392

Rodríguez-Moñino, Antonio (1976): Los pliegos poéticos de la Biblioteca colombina (siglo XVI). Estudio bibliográfico. Berkeley / Los Angeles / London, University of California Press.

Rodríguez-Moñino, Antonio (1997): Nuevo Diccionario bibliográfico de pliegos sueltos poéticos (siglo XVI). Edición corregida y actualizada por Arthur L.-F. Askins y Víctor Infantes, Madrid, Editorial Castalia / Editora Regional de Extremadura. Abrevio: NDicc. más el número de la ficha del pliego.

Fecha de recepción: 3 de julio de 2021

Fecha de aceptación: 16 de septiembre de 2021

$$
\text { i }
$$

